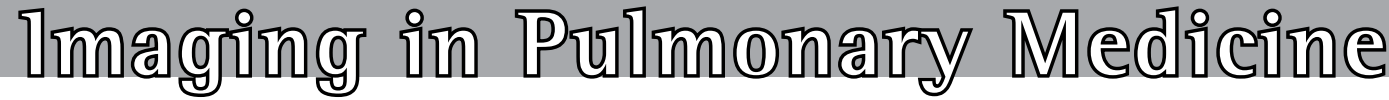

\section{Pulmonary cement embolism}

\author{
Embolia pulmonar por cimento ósseo \\ Manuel Lessa Ribeiro Neto' ${ }^{1}$, Marcel Lima Albuquerque ${ }^{1}$, \\ Daniela Barboza Santos Cavalcante ${ }^{1}$, João Ricardo Maltez de Almeida ${ }^{2}$
}

A 74-year-old woman, who had peptide and troponin 1 were normal $(65.5 \mathrm{pg} / \mathrm{mL}$ undergone spinal fusion with vertebroplasty and $<0.01 \mathrm{ng} / \mathrm{mL}$, respectively). Doppler ultrasound (polymethylmethacrylate cement injection) for of the lower extremities showed no deep vein osteoporotic fractures three years prior, presented with a one-month history of dyspnea on exertion. Her blood pressure was 164/90 mmHg. Her electrocardiogram was normal, and arterial blood gas analysis showed no hypoxemia. Brain natriuretic

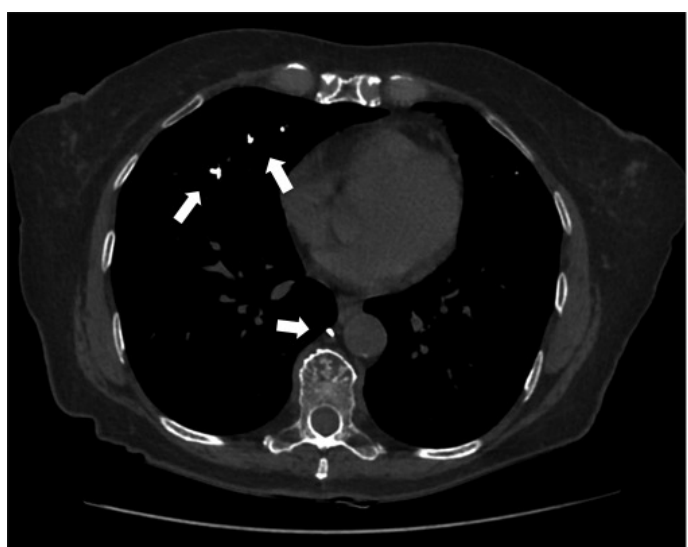

Figure 1 - Axial CT image. White arrows indicate embolized polymethylmethacrylate in the azygos system and pulmonary arteries.

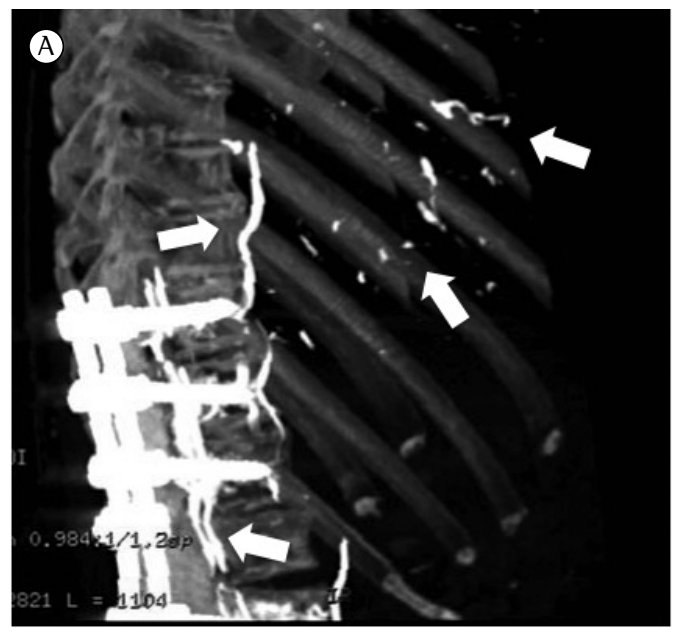

thrombosis, and echocardiography showed left ventricular diastolic dysfunction (grade 1) with no right-sided abnormalities. Chest CT showed embolized polymethylmethacrylate cement in the azygos system and pulmonary arteries (Figures 1 and 2, respectively). Anticoagulation therapy was started.

Although pulmonary cement embolism (PCE) is a known complication of vertebroplasty, its exact incidence remains controversial, reportedly ranging from $2.1 \%$, in a retrospective study, ${ }^{(1)}$ to $24.0 \%$, in a prospective study. ${ }^{(2)}$ In the former study, ${ }^{(1)}$ all PCE patients remained asymptomatic for the first year of follow-up; in the latter, ${ }^{(2)}$ most of the emboli were small and peripheral. However, symptoms can develop, and fatal events have been reported. ${ }^{(2)}$

In a systematic review, Krueger et al. ${ }^{(3)}$ identified no best management strategy but concluded that PCE patients with symptomatic peripheral

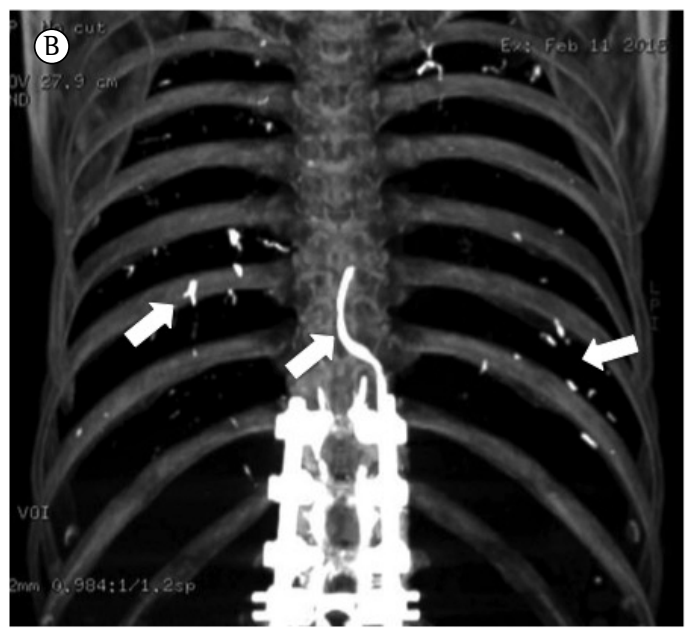

Figure 2 - CT image reconstructed with three-dimensional maximum intensity projection in the sagittal oblique plane $(\mathrm{A})$ and coronal plane (B). White arrows indicate high attenuation material corresponding to polymethylmethacrylate in the paravertebral venous plexus, extending into the hemiazygos vein and embolized to pulmonary vessels.

1. Serviço de Medicina Respiratória, Hospital Cárdio Pulmonar, Salvador, Brasil.

2. Serviço de Bioimagem, Hospital Cárdio Pulmonar, Salvador, Brasil. 
embolisms should receive full anticoagulation for six months.

\section{Recommended reading}

1. Venmans A, Lohle PN, van Rooij WJ, Verhaar HJ, Mali WP. Frequency and outcome of pulmonary polymethylmethacrylate embolism during percutaneous vertebroplasty. AJNR Am J Neuroradiol. 2008;29(10):1983-5. http://dx.doi.org/10.3174/ajnr.A1269
2. Kim YJ, Lee JW, Park KW, Yeom JS, Jeong HS, Park JM, et al. Pulmonary cement embolism after percutaneous vertebroplasty in osteoporotic vertebral compression fractures: incidence, characteristics, and risk factors. Radiology 2009;251(1):250-9. http://dx.doi.org/10.1148/ radiol.2511080854

3. Krueger A, Bliemel C, Zettl R, Ruchholtz S. Management of pulmonary cement embolism after percutaneous vertebroplasty and kyphoplasty: a systematic review of the literature. Eur Spine J. 2009;18(9):1257-65. http:// dx.doi.org/10.1007/s00586-009-1073-y 